\title{
AN EDDY CURRENT SEPTUM MAGNET PROTOTYPE FOR SOLEIL LIGHT SOURCE PROJECT ${ }^{*}$
}

\author{
J.C. Ciret, G. Congretel, C. Evesque, $\underline{\text { P. Gros }}$
}

CEA Saclay FRANCE, IN2P3 Orsay France

\begin{abstract}
One of the prototypes which has been made during the $2.5 \mathrm{GeV}$ synchrotron project SOLEIL design is a passive septum magnet. Standard cross section has been chosen for the three eddy current septum magnets used for the booster injection, the booster extraction and the storage ring injection of SOLEIL. A prototype for SOLEIL project has been realized. In this paper the comparison between $2 d \& 3 d$ calculations (OPERA-2d, ELEKTRA) and results of magnetic measurements is presented, as well as results of thermal tests in vacuum and influence of all of these on mechanical design for the final magnet.
\end{abstract}

\section{INTRODUCTION}

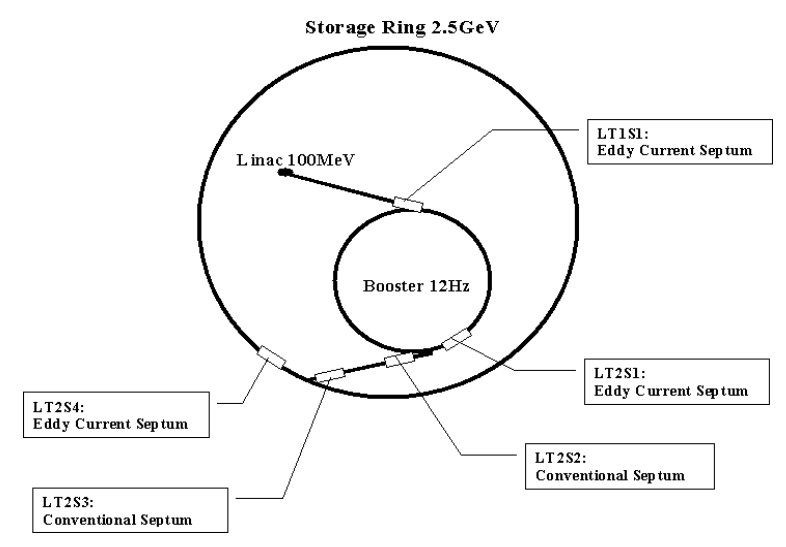

Figure 1: SOLEIL survey

SOLEIL [1] is a Synchrotron Radiation Facility. Electrons are accelerated, via a $100 \mathrm{MeV}$ linac and a $2.5 \mathrm{GeV}-12 \mathrm{~Hz}$ synchrotron booster, then injected into the storage ring (Figure 1). The booster extraction as well as the storage ring injection scheme are based on the one at ESRF [2].

A machine like SOLEIL needs eddy current septum magnets to carry out its booster injection-extraction and its storage ring injection schemes (Figure 1). It is due to the closeness between kicked and circulating (non kicked) beams at this level of energy $(2.5 \mathrm{GeV})$. In this case a thin copper sheet flowed by induced eddy currents is the only way to shield the main pulsed magnetic field from the circulating beam which needs a low stray field.

A great constraint in such a design is the situation of the device under vacuum $\left(10^{-11} \mathrm{~T}\right.$ for the storage ring) which involves specific electro-mechanical solutions.

Moreover to increase reliability, thus minimizing the machine stopping, the magnet should be naturally cooled by conduction.

poster showed at the $16^{\text {th }}$ International Conference on Magnet Technology, September 26 - October 2, 1999, Ponte Vedra Beach, Florida, USA

\section{CALCULATION AND DESIGN}

A unique prototype design may be sufficient for satisfying all the criteria described in the earlier chapter.

Table 1: magnet main characteristics

\begin{tabular}{|c|c|c|}
\hline Vertical gap: & 15 & $\mathrm{~mm}$ \\
\hline Horizontal aperture: & 30 & $\mathrm{~mm}$ \\
\hline Nominal field: & 0.5025 & $\mathrm{~T}$ \\
\hline Ampere-turns: & 6000 & AT \\
\hline Turns: & 1 & \\
\hline Mechanical length: & 250 & $\mathrm{~mm}$ \\
\hline Magnetic length: & 269 & $\mathrm{~mm}$ \\
\hline Current pulse: & $60 \mu \mathrm{s} 1 / 2$ sine & \\
\hline Septum thicknesses: & $1.5: 3$ & $\mathrm{~mm}$ \\
\hline Cond. cross section $\mathrm{HxV}$ : & $4 \times 14.4$ & $\mathrm{~mm}^{2}$ \\
\hline Self induction: & 750 & $\mathrm{nH}$ \\
\hline Cooling: & natural & \\
\hline
\end{tabular}

The yoke is laminated with about 1200 steel pressed sheets. Each sheet is grain oriented, $0.23 \mathrm{~mm}$ thick, Fe with Si 3\% composed, double coated with silicate of magnesium and a phosphate deposit (UGINE M3X23). The mechanical design gives two septum thickness testing possibilities: 1.5 and $3 \mathrm{~mm}$.

The coil insulation is obtained from an alumina plasma spray under pressure. This has been done to adhere to the vacuum criteria as well as to maintain mechanical reliability.

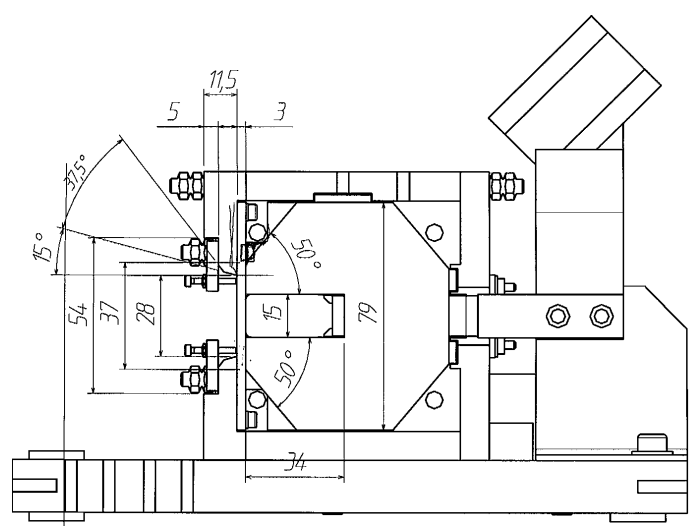

Figure 2: prototype magnet cross section

Except for the global load resistance and self induction, thus the total losses and voltage scale, a $250 \mathrm{~mm}$ reduced yoke length is sufficient for both design and measurement (Figures $3 \& 4$ ). It allows not using a too huge pulsed power supply prototype. 


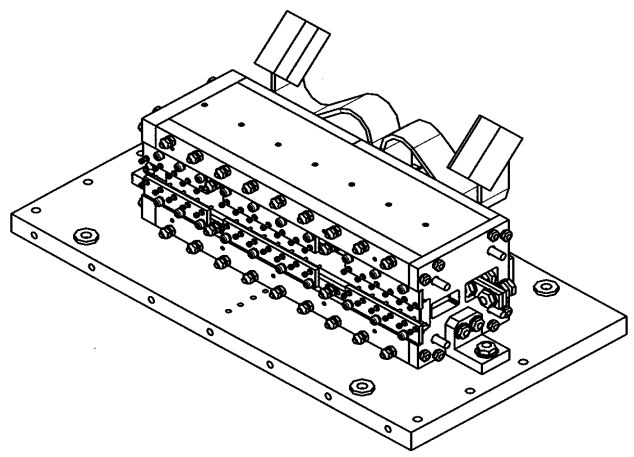

Figure 3: prototype global front view

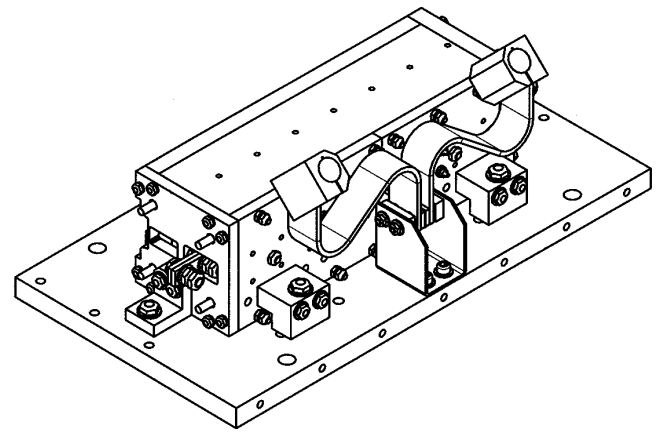

Figure 4: prototype global rear view

The field homogeneity $\frac{\Lambda B}{B n o m}$ in the "beam stay clear" area has to be better than $0.5 \%$ (Figures $5 \& 6$ ).

The OPERA-2d [3] code gives the standard cross section design (Figures $5 \& 6$ ); the 3 d ELEKTRA [3] lets us optimize the edge fringe field shape, to determine the magnetic length, eddy current circulation and losses evaluation (Figure 8).

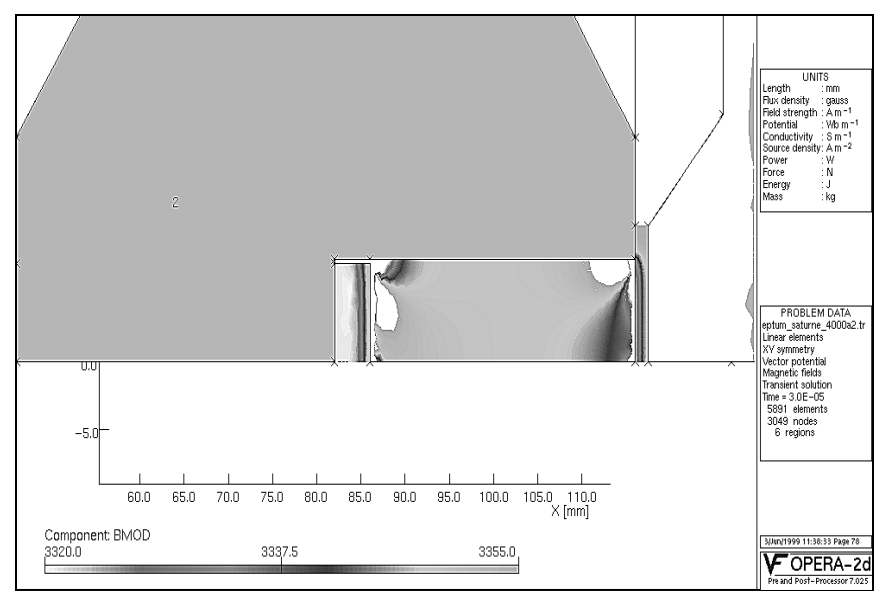

Figure 5: main field and current density

Figure 5 shows both the magnetic field homogeneity and the electrical skin depth (about $0.7 \mathrm{~mm}$ ) in the coil conductor as well as in the septum.

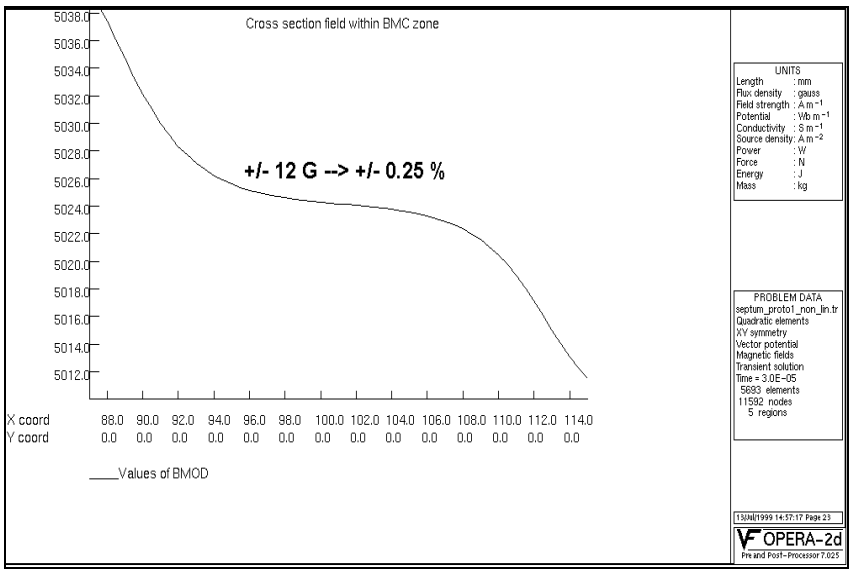

Figure 6: cross section field

The stray field integral $\int B_{\text {stray }} \cdot d l$ should be less than $5 \mathrm{Gm}$ for the $2.5 \mathrm{GeV}$ circulating beam.

The design underlines a delay between the maximum fringe field and the main field peak (Figure 7).

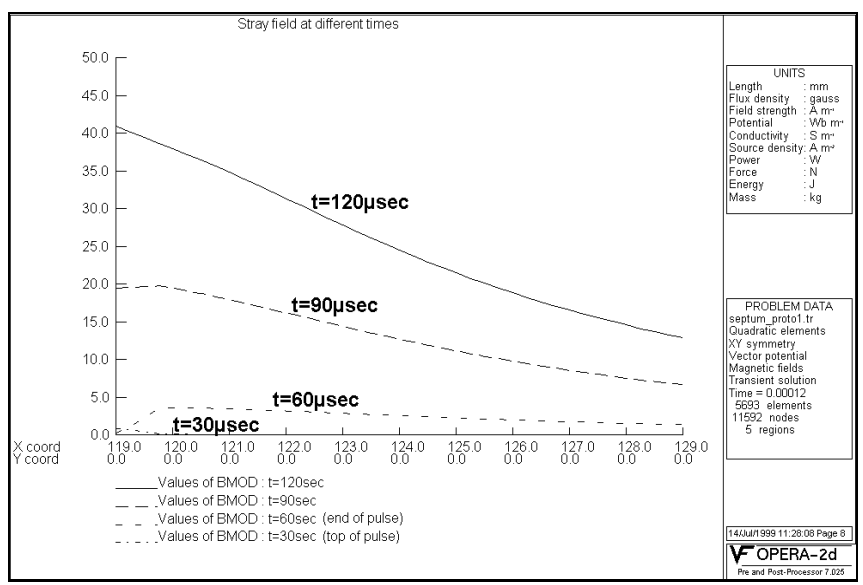

Figure 7: stray field at different times

Figure 8 shows the not negligible $3 \mathrm{~d}$ shape of the stray field at $60 \mu$ s just after the pulse.

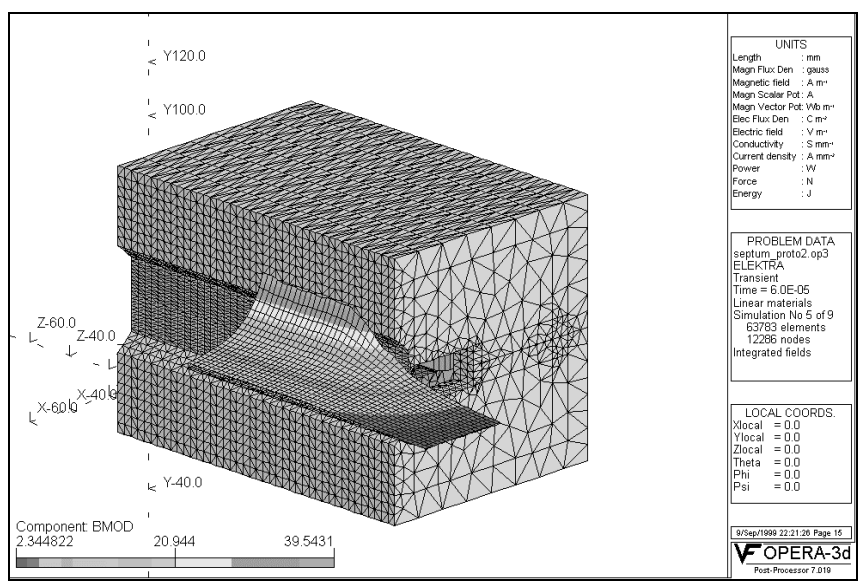

Figure 8: 3d stray field shape at $60 \mu$ s (end of pulse) 
The codes run on HP/9000 station under HP-UX and the solving time of such a $3 \mathrm{~d}$ case (Figure 8 ) is about 24 hours with 64000 elements, $t=0$ to $120 \mu$ s and a $5 \mu$ s step.

\section{MAGNETIC MEASUREMENTS}

The measuring equipment consists of :

- 2 types of narrow coils

- a short one for the main field level measurement

- a long one for the magnetic length determination

- a high accuracy current transformer

- a digital integrator oscilloscope

- the pulsed power supply, based on ESRF design [4]

Figure 9 shows the three useful signals for the measurement understanding:

- the current signal (sine wave)

- the coil signal (cosine wave)

- the field deduced from coil signal integration (upside down sine wave)

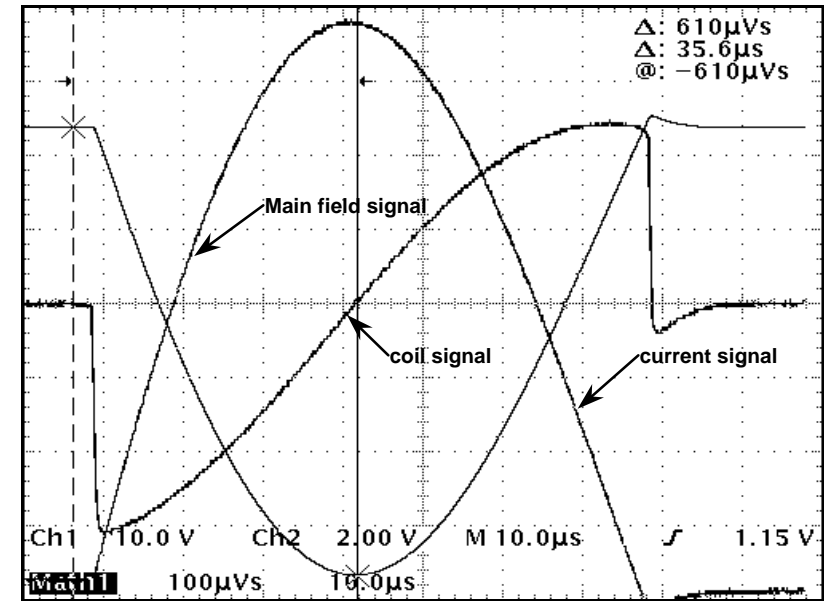

Figure 9: main field measurement signals

Figure 10 shows the delay between the maximum fringe field and the main field peak, confirming the simulations.

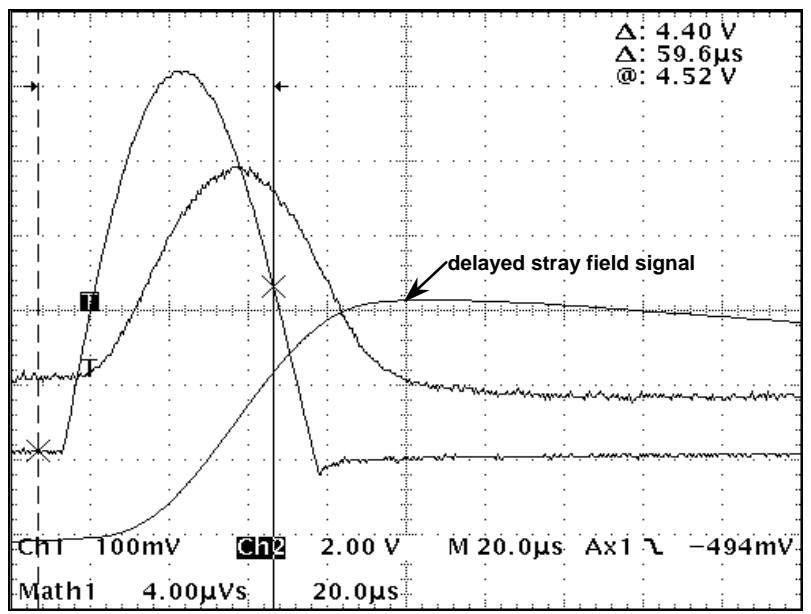

Figure 10: stray field measurement signals
On Figure 11, we can observe a $5 \%$ difference between the calculated and measured field. This attenuation is due to losses inside the laminated yoke which are not taken into account by the simulating code.

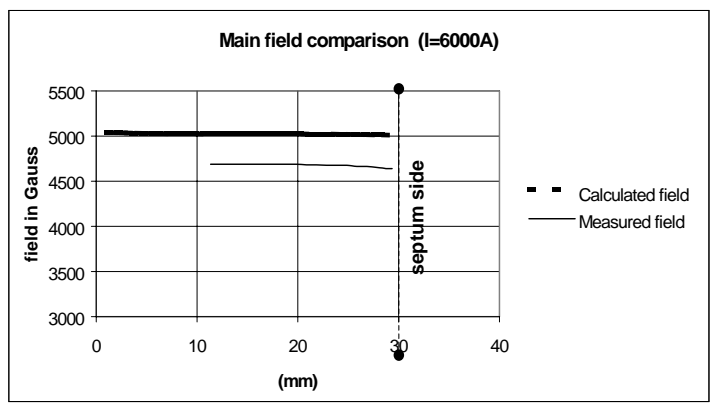

Figure 11: calculated and measured main field

However there is an agreement between simulated and measured fringe field (Figure 12).

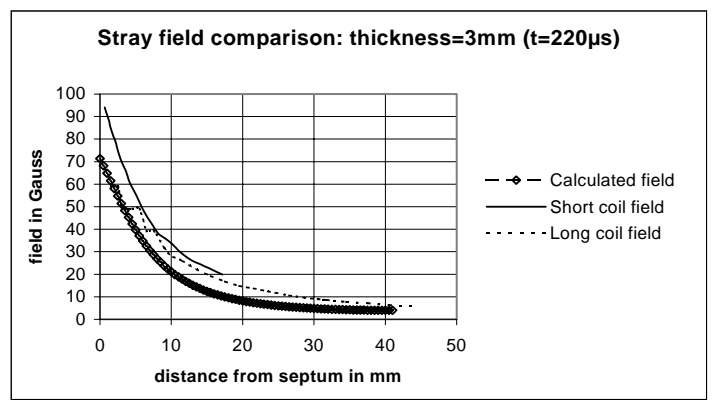

Figure 12: calculated and measured stray field

\section{THERMAL TESTS UNDER VACUUM}

The magnet is installed for baking in a vacuum tank with its heating, pumping and measurement devices:

- a hybrid turbo-molecular pump

- a Ti sublimation pump

- a Bayard-Alpert gauge

- a residual gas analyzer

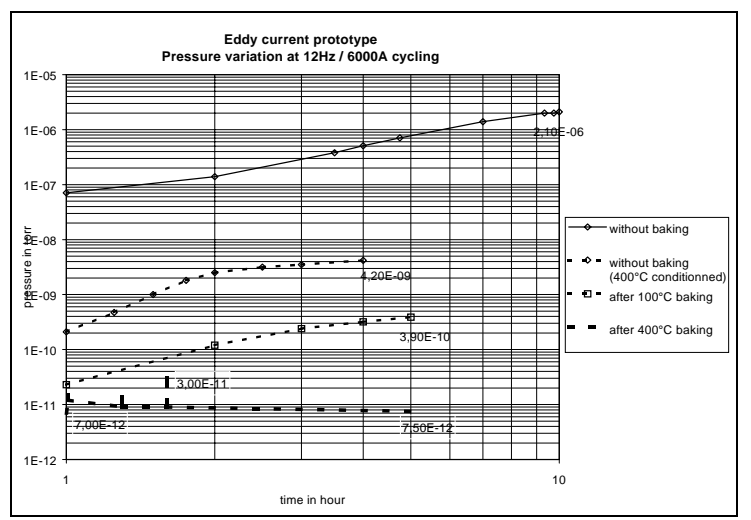

Figure 13: vacuum level before and after several bakings 
The outgassing tests for an iron sheets sample $\left(\approx 5 \mathrm{~m}^{2}\right)$ give a rate $\alpha=1.3 .10^{-11} \mathrm{t} .1 / \mathrm{s} . \mathrm{cm}^{2}$ after 1 hour and finally $1.4 .10^{-13}$ t. $1 / \mathrm{s} . \mathrm{cm}^{2}$ after 100 hours of relaxation baking. These tests are all relevant to the NF X 10-507 standard.

The results of the tests imply 4 main recommendations:

1) An UHV treatment for all materials.

2) A high temperature $\left(800^{\circ} \mathrm{C}\right)$ conditioning for the magnet before the mounting in situ.

3) A high in situ baking temperature $\left(400{ }^{\circ} \mathrm{C}\right)$, only for the storage ring magnet.

4) A lower baking temperature $\left(100^{\circ} \mathrm{C}\right)$ for the two booster magnets.

\section{DESIGN DETAILS FOR SOLEIL}

As a result of the tests, these modifications have been made to the final design:

- The connections have been revised to reduce the global load self-inductance seen from the pulsed power supply (Figure 15)

- The electrical contact optimization between the septum edges and the extremity flanges of the magnet copper shielding box

- The yoke centering inside the box for an edge stray field minimization

- A better coil shielding near the beam path at the edge aperture zone

Figure 14 shows the trap chamber mounting (partial) along the storage ring magnet septum. It essentially provides two functions:

- A differential vacuum between the circulating stored beam and the transfer line from the booster

- A good beam impedance continuity in the storage ring vacuum chamber

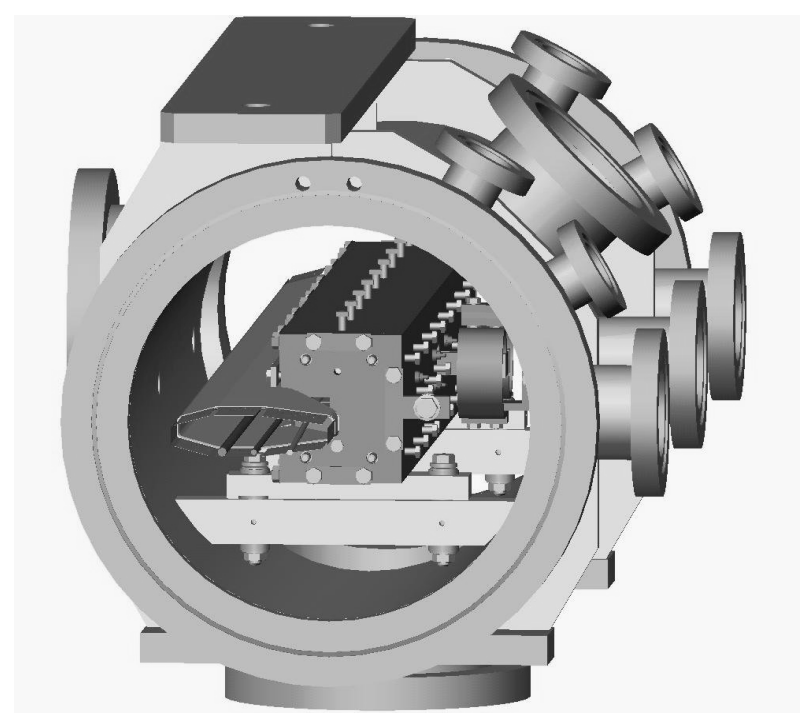

Figure 14: view of the storage ring magnet

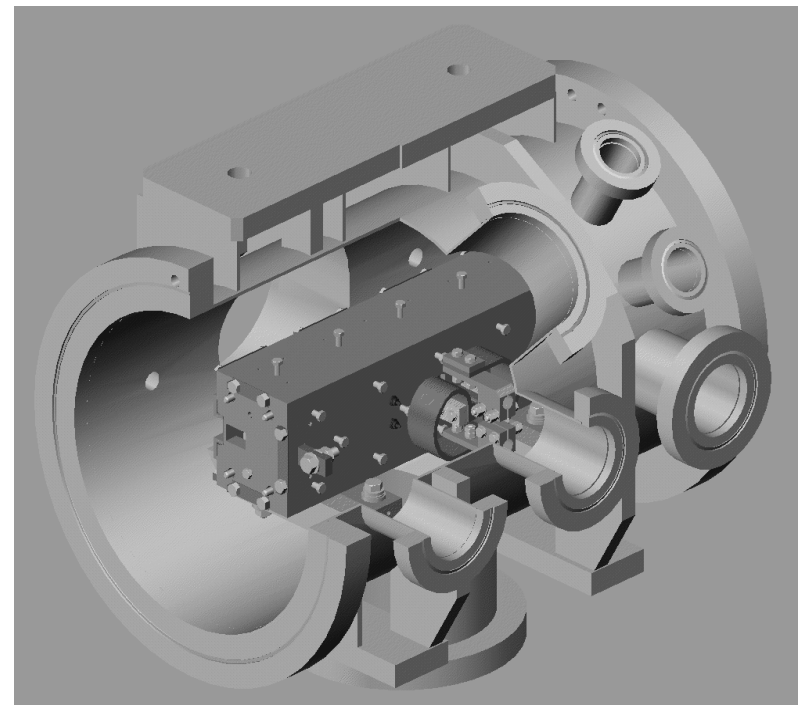

Figure 15: view of the booster magnets

\section{CONCLUSION}

This design has been very useful in helping to understand the mechanical and electrical difficulties encountered with eddy current septum magnets. It has also been a good bench mark for the used $2 \mathrm{~d}$ and $3 \mathrm{~d}$ simulation codes.

\section{REFERENCES}

[1] SOLEIL “Rapport d'avant projet détaillé”, Juin 1999

[2] “ESRF Foundation Phase Report”, February 1987

[3] OPERA-2d, OPERA-3d ELEKTRA finite element codes from Vector Fields Ltd Kidlington, UK

[4] J.P. Perrine ESRF, M. Thivent \& F. Völker CERN “The pulsed power converter and septum magnet system for injection into the electron storage ring at ESRF", EPAC '96 Sitges, Barcelona, Spain 